\title{
Are we operating unnecessarily?: caesarean audit in a single unit of a private tertiary care hospital in North India
}

\author{
Nidhi Singh ${ }^{1 *}$, Manjusha ${ }^{2}$
}

\begin{abstract}
${ }^{1}$ Department of Obstetrics and Gynecology, Prasad Institute of Medical Sciences, Lucknow, Uttar Pradesh, India
${ }^{2}$ Department of Obstetrics and Gynecology, Sahara Hospital, Lucknow, Uttar Pradesh, India
\end{abstract}

Received: 05 February 2020

Accepted: 11 February 2020

\author{
*Correspondence: \\ Dr. Nidhi Singh, \\ E-mail: dr.nidhikgmc99@gmail.com
}

Copyright: (c) the author(s), publisher and licensee Medip Academy. This is an open-access article distributed under the terms of the Creative Commons Attribution Non-Commercial License, which permits unrestricted non-commercial use, distribution, and reproduction in any medium, provided the original work is properly cited.

\begin{abstract}
Background: Caesarean section emerged as a lifesaving surgery in situations where vaginal delivery could put the mother and fetus at risk. Over the years global rise in caesarean delivery rate has been alarming and may be attributed to changes in medical practice and societal expectations, especially in urban areas and developing countries. Rising caesarean rate is worrisome as it increases maternal morbidity, exposes the mother to future obstetric risks, besides increasing financial burden on the health care system. Caesarean audits could be an effective tool to analyse, understand and propose solutions to reduce caesarean rates. Hence, this retrospective study was conducted to audit caesarean sections done over a period of 5 years (2011 to 2015) in a single unit of a tertiary care private hospital in North India.

Methods: The case records of all caesarean deliveries from January 2011 to December 2015 were analysed retrospectively for demographic profile, clinical parameters and recorded indication of caesarean section on the basis of Robson's classification.

Results: The caesarean section rate in the study was $61.8 \%$. According to Robson's 10 system classification, Group 2, 5 and 10 were the largest contributors. The commonest indication was previous LSCS (18.7\%) followed closely by fetal distress (15.4\%) and prolonged labor/failed induction (13.3\%). Maternal request contributed $10.6 \%$ of the Caesarean deliveries.

Conclusions: The caesarean section rate in our study is way higher than the national average. We need to re-duce caesareans in primigravidae and consider VBAC where appropriate. Use of Electronic fetal monitoring during labor needs to be optimized. Appropriate use of oxytocics, proper monitoring and using robust criterion to infer non progress of labor are important. Appropriate counselling and assured pain management during labor may help reduce caesareans on maternal request.
\end{abstract}

Keywords: Caesarean section, Caesarean audit, Robson's classification, Tertiary hospital

\section{INTRODUCTION}

Caesarean section (Cs) is a commonly performed surgical procedure aimed to reduce maternal and perinatal morbidity- mortality. Although WHO has stated that there is no benefit of $\mathrm{Cs}$ beyond $10-15 \%$ at community level, every fifth woman undergoes the procedure. ${ }^{1}$ The incidence of Cs has been steadily rising globally. Rise in caesarean section rates, especially in urban set-ups in third world countries is alarming. There is a need to audit the indications in order to find reasons for uncalled for caesarean deliveries and devise new strategies to curb the trend.

\section{METHODS}

The study was conducted at Sahara Hospital, Lucknow which is a state of art tertiary care and referral center. It 
was a retrospective observational study conducted in a single consultant unit of obstetrics and gynecology department of the hospital. The study period was from $1^{\text {st }}$ January 2011 to $31^{\text {st }}$ December 2015. All patients who delivered during this period were identified from the birth register and the case records of all caesarean deliveries conducted in the unit during the study period were analysed.

Data was collected to include the demographic profile of patients (age, educational qualification, profession, religion), details of pregnancy (parity, gestational age, singleton or multiple pregnancy, lie and presentation, previous caesareans, high risk factors), intrapartum events, mode of delivery and indications of caesarean section.

Indications were then classified using Robson's ten group classification system as follows.

- Group 1: Nulliparous, single cephalic, >= 37 weeks, in spontaneous labour.

- Group 2: Nulliparous, single cephalic, >= 37 weeks, induced (including pre-labour CS).

- Group 3: Multiparous (excluding previous CS), single cephalic, >= 37 weeks, spontaneous labour. Group 4: Multiparous (excluding previous CS), single cephalic, $>=37$ weeks, induced labour (including pre labour CS)

- Group 5: Previous CS, single cephalic, $\geq 37$ weeks.

- Group 6: All Nulliparous breeches.

- Group 7: All multiparous breeches (including previous CS).

- Group 8: All multiple pregnancy (including previous CS).

- Group 9: All transverse/ oblique lies (including previous CS).

- Group 10: All preterm single cephalic, < 37 weeks including previous $\mathrm{CS}$.

Robson's Classification was used firstly to identify the group of patients with increased rate of caesarean delivery. Secondly, to help in the audit process so that trends in caesarean section rates can be monitored over time and lastly to identify the low risk cohort of women who could be targeted to reduce caesarean section rate by changing intrapartum protocols.

\section{RESULTS}

The number of deliveries conducted in our unit from $1^{\text {st }}$ January 2011 till $31^{\text {st }}$ December 2015 were 597. Out of these, 369 were caesarean deliveries for various reasons, making the overall $\mathrm{Cs}$ rate as $61.8 \%$. The Cs rate increased from $53.6 \%$ (in 2011), to peak at $66.9 \%$ (in 2013) and then decreased to $61.2 \%$ (in 2015) (Table 1).

The majority of women were in the age group 26-30 years $(55 \%)$ and were primigravidae $(52.3 \%)$. Majority of women $(52.3 \%)$ were post-graduates and $36.8 \%$ were skilled professionals (Table 2). Most women in our cohort $(95 \%)$ had singleton cephalic pregnancies while only about $5 \%$ had fetal malpresentations/ multiple pregnancies.

Table 1: Year-wise CS rate.

\begin{tabular}{|llll|}
\hline Year & $\begin{array}{l}\text { Total no. of } \\
\text { deliveries }\end{array}$ & $\begin{array}{l}\text { Number of } \\
\text { CS }\end{array}$ & \% CS \\
\hline 2011 & 97 & 52 & $53.6 \%$ \\
\hline 2012 & 107 & 64 & $59.8 \%$ \\
\hline 2013 & 142 & 95 & $66.9 \%$ \\
\hline 2014 & 135 & 87 & $64.4 \%$ \\
\hline 2015 & 116 & 71 & $61.2 \%$ \\
\hline Total & $\mathbf{5 9 7}$ & $\mathbf{3 6 9}$ & $\mathbf{6 1 . 8 \%}$ \\
\hline
\end{tabular}

Table 2: Demographic profile of women delivering by caesarean section during the study period.

\begin{tabular}{|lll|}
\hline \multicolumn{1}{|l}{ Number } & Percentage \\
\hline $15-20$ & 2 & $0.5 \%$ \\
\hline $21-25$ & 71 & $19.2 \%$ \\
\hline $26-30$ & 200 & $54.2 \%$ \\
\hline $31-35$ & 85 & $23.1 \%$ \\
\hline $36-40$ & 11 & $3 \%$ \\
\hline Parity & & \\
\hline Primigravida & 192 & $52.2 \%$ \\
\hline P1 & 118 & $31.9 \%$ \\
\hline$>=$ P2 & 59 & $15.9 \%$ \\
\hline Education & & \\
\hline Post-grad & 193 & $52.3 \%$ \\
\hline Graduate & 154 & $41.8 \%$ \\
\hline$<=12$ grade & 22 & $5.9 \%$ \\
\hline Profession & & \\
\hline Homemaker & 233 & $63.2 \%$ \\
\hline Working profession & 136 & $36.8 \%$ \\
\hline Religion & & \\
\hline Hindu & 313 & $84.8 \%$ \\
\hline Muslim & 51 & $0.8 \%$ \\
\hline Sikh & 3 & $0.2 \%$ \\
\hline Christian & 1 & $0.2 \%$ \\
\hline Buddhist & 1 & \\
\hline & & \\
\hline
\end{tabular}

The commonest indication of Cs was previous LSCS (18.7\%), followed by fetal distress (15.4\%) and prolonged labor/ failed induction (13.3\%). Maternal request was the reason for $10.6 \%$ of the Caesareans in the study period. Around $18.9 \%$ caesareans were contributed by other indications like PPROM with severe oligohydramnios or impending chorioamnionitis, IUGR with absent diastolic umbilical flow, precious pregnancy and large babies. Few special cases included pregnancy with bilateral ovarian masses, metastatic disease, maternal heart failure (Table 3). 
The data collected was then analyzed using Robson's ten group classification system to enable scientific evaluation, identify shortcomings and devise strategies to improve practices (Table 4). The single largest contributor of $\mathrm{Cs}$ in our study was Group 2 i.e. nulliparous women with single-ton cephalic fetus, induced at term $(35.3 \%)$. Within this group, $31.5 \%$ cases were due to non-progress of labour, $16.9 \%$ for fetal distress, $13.8 \%$ were due to maternal request to convert, $10.8 \%$ were due to nuchal cord related issues, $10 \%$ due to cephalo-pelvic disproportion, $5.4 \%$ were hastened due to impending eclampsia and $11.5 \%$ due to miscellaneous reasons.

Table 3: Year-wise caesarean section rate according to indications.

\begin{tabular}{|c|c|c|c|c|c|c|}
\hline $\begin{array}{l}\text { Indications for } \\
\text { caesarean section }\end{array}$ & $\begin{array}{l}2011 n=52 \\
(\%)\end{array}$ & $\begin{array}{l}2012 n=64 \\
(\%)\end{array}$ & $\begin{array}{l}2013 n=95 \\
(\%)\end{array}$ & $\begin{array}{l}2014 n=87 \\
(\%)\end{array}$ & $\begin{array}{l}2015 \mathrm{n}=71 \\
(\%)\end{array}$ & $\begin{array}{l}\text { All five years } \\
(2011-2015) n= \\
369(\%)\end{array}$ \\
\hline Fetal distress & $9(17.3 \%)$ & $11(17.1 \%)$ & $7(7.36 \%)$ & $24(27.5 \%)$ & $6(8.5 \%)$ & $57(15.4 \%)$ \\
\hline Previous LSCS & $13(25 \%)$ & $10(15.6 \%)$ & $18(18.9 \%)$ & $10(11.4 \%)$ & $18(11.3 \%)$ & $69(18.69 \%)$ \\
\hline $\begin{array}{l}\text { Malposition or } \\
\text { malpresentation }\end{array}$ & $2(3.8 \%)$ & $2(3.1 \%)$ & $6(6.3 \%)$ & $3(3.44 \%)$ & $4(5.63 \%)$ & $17(4.6 \%)$ \\
\hline $\begin{array}{l}\text { Prolonged labour/failed } \\
\text { induction }\end{array}$ & $7(13.4 \%)$ & $12(18.7 \%)$ & $14(14.7 \%)$ & $7(8.04 \%)$ & $9(12.6 \%)$ & $49(13.3 \%)$ \\
\hline Maternal request & $8(15.3 \%)$ & $9(14.1 \%)$ & $10(10.5 \%)$ & $9(10.3 \%)$ & $6(8.5 \%)$ & $39(10.6 \%)$ \\
\hline $\begin{array}{l}\text { Cephalopelvic } \\
\text { disproportion }\end{array}$ & $3(5.7 \%)$ & $3(4.6 \%)$ & $6(6.3 \%)$ & $6(6.9 \%)$ & $6(8.5 \%)$ & $24(6.5 \%)$ \\
\hline $\begin{array}{l}\text { Hypertensive disorders } \\
\text { of pregnancy }\end{array}$ & $4(7.6 \%)$ & $5(7.8 \%)$ & $11(11.6 \%)$ & $8(9.2 \%)$ & $5(7.04 \%)$ & $33(8.9 \%)$ \\
\hline $\begin{array}{l}\text { Antepartum } \\
\text { haemorrhage (APH) }\end{array}$ & $1(1.9 \%)$ & $4(6.2 \%)$ & $2(2.1 \%)$ & $1(1.5 \%)$ & $2(2.8 \%)$ & $10(2.7 \%)$ \\
\hline $\begin{array}{l}\text { Bad obstetric history } \\
(\mathrm{BOH})\end{array}$ & $4(7.6 \%)$ & $1(1.5 \%)$ & $1(1.1 \%)$ & $1(1.5 \%)$ & $1(1.4 \%)$ & $8(2.1 \%)$ \\
\hline Others & $1(1.9 \%)$ & $12(18.7 \%)$ & $20(21.1 \%)$ & $18(20.6 \%)$ & $14(19.7 \%)$ & $70(18.9 \%)$ \\
\hline
\end{tabular}

Table 4: Robson's ten system classification with contribution of each group in the overall caesarean section rate.

\begin{tabular}{|llll|}
\hline Group & Description & $\begin{array}{l}\text { No. of C- } \\
\text { sections }\end{array}$ & $\begin{array}{l}\text { Percentage of total } \\
\text { C-sections (n= 369) }\end{array}$ \\
\hline Group 1 & Nulliparous, single cephalic, $\geq 37$ weeks, in spontaneous labour & 35 & $9.4 \%$ \\
\hline Group 2 & $\begin{array}{l}\text { Nulliparous, single cephalic, } \geq 37 \text { weeks, induced labour } \\
\text { (including prelabour CS) }\end{array}$ & 130 & $35.3 \%$ \\
\hline Group 3 & $\begin{array}{l}\text { Multiparous (excluding previous CS), single cephalic, >= 37 } \\
\text { weeks, spontaneous labour }\end{array}$ & 5 & \multirow{2}{*}{$1.36 \%$} \\
\hline Group 4 & $\begin{array}{l}\text { Multiparous (excluding previous CS), single cephalic, >=37 } \\
\text { weeks, induced labour (including pre labour CS) }\end{array}$ & 13 & $3.52 \%$ \\
\hline Group 5 & Previous CS, single cephalic, $\geq 37$ weeks & 93 & $25.20 \%$ \\
\hline Group 6 & All nulliparous breeches & 9 & $2.4 \%$ \\
\hline Group 7 & All multiparous breeches (including previous CS) & 3 & $0.81 \%$ \\
\hline Group 8 & All multiple pregnancy (including previous CS) & 6 & $1.62 \%$ \\
\hline Group 9 & All transverse/ oblique lies (including previous CS) & 1 & $0.27 \%$ \\
\hline Group 10 & All preterm single cephalic, <37 weeks including previous CS & 74 & $20.05 \%$ \\
\hline
\end{tabular}

A quarter of women were in Group 5 i.e., repeat Cs for singleton cephalic fetus at term $(25.2 \%)$.

Robson's Group 10 i.e., preterm singleton cephalic pregnancies followed closely $(20.05 \%)$, indicating that a large number of preterm deliveries were conducted in our unit. Detailed analysis revealed that $22.9 \%$ of these were done for hypertensive disorders of pregnancy (including severe pre-eclampsia, impending eclampsia, eclampsia and HELLP syndrome), $17.5 \%$ were done for suspected scar dehiscence and $13.5 \%$ were done for PPROM with impending chorioamnionitis. Other reasons for preterm delivery were abnormal Doppler parameters (6.7\%), ominous CTG $(8.1 \%)$, antepartum hemorrhage $(5.4 \%)$ and severe oligohydramnios $(6.4 \%)$.

Robson's Group 1 contributed about 9\% (35) of Cs deliveries. The indications here were fetal dis-tress in 
$34.2 \%$, non-progress of labour in $31.4 \%$, maternal request to convert to $\mathrm{Cs}$ in $17.1 \%$, cephalo-pelvic disproportion and impending eclampsia in $8.5 \%$ each. The groups 3,4 , $6,7,8$ and 9 made only meagre contributions.

\section{DISCUSSION}

Rising caesarean section rates have serious implications on maternal health, besides increasing financial burden on the health care system. Indian Council of Medical Research (ICMR) has re-ported a rise in Cs rates from $21.8 \%$ in $1993-94$ to $25.4 \%$ in $1998-99$, in a study conducted at 30 teaching hospitals in India. ${ }^{2}$ Ghosh $\mathrm{S}$ et al, have also reported a rising trend on comparing the three national rates: $2.9 \%$ (NFHS 1,1992-93), $7.1 \%$ (NFHS-2, 1998-99) and 10.2\% (NFHS -3, 2005-2006). ${ }^{3}$ WHO considers Cs rate of $15 \%$ at community level optimal; they suggest that higher rates are unnecessary as they do not improve feto-maternal outcome. Although the authors genuinely intend to work towards reducing $\mathrm{Cs}$ rates, they are of the opinion that ensuring optimal outcome for each individual woman is much more important than attempting to achieve impressive community statistics.

We have evaluated 369 women who underwent Cs between 2011-15 at our world class, tertiary care, stateof-the-art corporate hospital in northern India. Our cohort had older, more qualified women, mostly from the upper socio-economic strata. They were obviously more demanding than the average Indian women. Obstetrics is not a pure science and we often had to modify our practices in order to incorporate wishes (demands) of our parturient.

The single largest contributor of Cs in our study was Robson's Group 2 i.e., nulliparous women with singleton cephalic fetus, induced at term $(35.3 \%)$. Most common reasons for $\mathrm{Cs}$ in this group were prolonged labour, fetal distress and maternal request.

We need to revisit the accuracy of diagnosis of "NonProgress of labour". Could we have waited longer is the obvious question? Impatience on the part of woman/ her family for longer trials, fear of litigation on our part in case of adverse perinatal outcome, logistic issues like longer decision-delivery intervals during odd hours may have contributed to early decision for caesareans during labour.

The common perception that labour lasting longer than 24 hours may lead to neonatal sepsis often forces the obstetrician to curtail an ongoing trial. Using the newer criteria of diagnosing active labour at $6 \mathrm{~cm}$ cervical dilatation is likely to reduce the incidence of "secondary arrest of dilatation in labour". In our opinion, constant support to the parturient, reassuring the attendants, strengthening the labour team and having stronger protocols in place for watchful expectancy during labour might help.
The diagnosis of fetal distress in our institution is based on fetal bradycardia on auscultation using doppler probe, meconium stained liquor or an ominous CTG. Procedures like amniotic lavage, fetal scalp sampling are not practiced and an urgent delivery is performed; Cs in first stage and instrumental delivery in the second. The "baby cried well at birth" does question the correctness of the diagnosis of distress, but can an obstetrician in private practice wait for a vaginal delivery in this situation, in today's era of frequent litigations against doctors?

However, use of CTG during labor needs to be optimized. CTG is known to be highly sensitive, poorly specific; it causes false alarm and many unnecessary caesarean deliveries. We can consider revisiting the policy of admission CTG for all women in labor. Continuous Electronic fetal monitoring should be used only when indicated and not universally for all laboring women.

Maternal request was another important contributor in our series. It one of the leading causes worldwide, accounting for 0.3 to $14 \%$ of all caesarean deliveries. ${ }^{4}$ Fear of pain, concerns about genital modification after vaginal delivery, lower tolerance to any complications or outcomes other than the perfect baby, convenience for health professionals and also for the mother and the family are the possible cause for increase in this trend. Some cultural factors are also contributory. There is a rising trend of scheduling Cs astrologically for designing the future of the baby. In case of private health sector, the fear of not finding her own doctor when labour begins could be a motive to program dates. Mackenzie et al observed that maternal request was one of the main indications for CS $(23 \%)$ in $1996 . .^{5}$

Maternal requests may sometimes be tackled with good counselling, compassionate nursing support and routine use of epidural analgesia. However, it may not be possible for us to argue against astrological beliefs of woman or her family in most circumstances.

The overall caesarean section rate over 5 years (20112015 ) in a single unit of our institution was $61.8 \%$. Bhardwaj et al have reported Cs rates of $48.1 \%$ from Madhya Pradesh, India. ${ }^{6}$ Another study from Chennai reported Cs rate of $50 \% .^{7}$ More recently, an ICMR task force study published in 2014, reported Cs rate from 30 teaching hospitals to be $28.1 \%$ in the years $2005-2006$. The range of $\mathrm{Cs}$ rate included a low of $11.6 \%$ at $\mathrm{BJ}$ medical College Pune to a high of $58.7 \%$ at MLN medical college Allahabad and 55.6\% at SSKM Hospital, Kolkata. ${ }^{8}$

NFHS-4 has reported Cs rate of 17.2\% (2015-2016) while NFHS-3 (2005-6) has reported a Cs rate of $23.7 \%$ for institutional deliveries. The rate is higher in the private health facilities compared to the public health facilities (29.9\% and $18.1 \%$ respectively). South East Asian region in particular has seen an unacceptable rise 
in CS rates. ${ }^{9}$ A study by Stanton in 2006 reported an annual rate of change of CS rates and found India to have the highest rates of rise in caesarean deliveries. ${ }^{10}$

Looking at the statistics from other countries, certain institutions in Brazil have reported very high rates (above $80 \%$ ) as compared to their national average of $47.7 \%$. The national CS rate in China is about 40.5\%. ${ }^{11}$ Although the overall caesarean rate in Africa is very low (3.5\%), largely due to underutilization of health facilities, certain centers in South Africa report CS rates up to $60 \% .^{12}$

WHO however considers the proportion of caesarean section to total births an indicator of availability of obstetric care (2009).

Our Cs rates too are far above the national statistics. The possible reasons for this are:

- $\quad$ Being a tertiary care center, we cater to women with multiple comorbidities

- Many sick, remote from term babies are referred to us for safe delivery and state-of-the-art neonatal care

- Sonographic diagnoses like nuchal cord, "early brain sparing effect" etc. along with half baked "GOOGLE knowledge" triggers the couples to demand Cs

- Very commonly in our practice, families like to choose the moment of birth. Many others find the uncertainty around trial of labour unacceptable. The prospective parents today re-fuse to accept anything but the perfect outcome, thus resulting in Cs on maternal request

- Reluctance of the parturient as well as obstetricians to undertake VBAC contributes to a large number of Cs. ${ }^{13,14}$

- Fear of litigation in private practice is a hanging sword, to which we give in often.

The authors make the following recommendations towards optimizing Cs rates:

- Induction of labour is more likely to result in Cs as compared to spontaneous onset of la-bour. It should be done only when really needed for obstetric reasons

- In order to reduce repeat Cs, we should genuinely attempt to reduce primary caesareans

- Consider the use of revised criteria for diagnosis of active stage of labour in order to reduce the incidence of "NPOL"

- VBAC should be considered whenever appropriate, subject to patient motivation, obstetric feasibility and availability of logistics

- Ensure proper counselling of woman and her family in antenatal period to encourage natural birth; availability of painless labour and a supportive companion during labour is likely to be beneficial

- Authors don't recommend watchful expectancy once fetal distress is suspected
- Authors feel that it is mostly impossible to argue against family's desire of "choosing the time of birth"

- Authors definitely consider the rising Cs rates as a major health issue but believe that ensuring optimum outcome for individual women is far more important than achieving impressive community statistics.

\section{CONCLUSION}

This caesarean audit study showed that the CS rate $(61.8 \%)$ in our unit was way higher than the reported national average. Group 2, 5 and 10 as per Robson's Classification were the largest contributors. It was concluded that special focus needs to be on reducing caesarean-sections in primi-gravidae by strengthening labour room protocols and vigilant supervised and intensive labour monitoring. Trial of labour to be given in previous caesareans to avoid repeat caesareans. Maternal request caesareans should be reduced to minimum by proper counselling, assurance and pain management during labour.

\section{Funding: No funding sources \\ Conflict of interest: None declared}

Ethical approval: The study was approved by the Institutional Ethics Committee

\section{REFERENCES}

1. World Health Organisation. Appropriate technology for birth. Lancet. 1985;326(8452):436-37.

2. Kambo I, Bedi N, Dillon BS, Saxena NC. A critical appraisal of caesarean section rates at teaching hospitals in India. Inter $\mathbf{J}$ Obstet Gynaecol. 2002;79:151-8.

3. Ghosh S. Increasing trends in caesarean section delivery in India, Role of medicalization of maternal. In Working Papers. The institute of Social and Economic Change, Bangalore; 2010.

4. McCourt C, wearer J, Statham H, Beake S, Gamble J, Creedy DK. Elective caesarean section and decision making: a critical review of literature. Birth. 2007;34;65-79.

5. Mackenzie IZ, Cooke I, Annan B. Indications for caesarean section in a consultant unit over the decade. J Obstet Gynecol. 2003;23:233-8.

6. Bharadwaj M, Modi J. four year audit of deliveries by caesarean section at a medical college hospital in Central India. Int $\mathrm{J}$ Reprod Contracept Obstet Gyenecol. 2015;4:1775-82.

7. Sreevidya S, Sathiyasekaran BW. High caesarean rates in Madras (India): a population based cross sectional study. Br J Obstet Gynecol. 2003;110:10611.

8. Dhillon BS, Chandhiok N, Bhatia BS, Coyaji KJ, Das MC, Das V, et al. Vaginal birth after caesarean section (VBAC) versus emergency caesarean section at teaching hospitals in India: an ICMR task force 
study. Int J Reprod Contracept Obstet Gynecol. 2014;3 (3):592-7.

9. Sajjad R, Ali CA, Iqbal A, Sajjad N, Haq MZ. An audit of caesarean sections in Military Hospital Rawalpindi. Anaesth Pain Intens Care. 2014;18(2):172-5.

10. Staton CK, Holtz Sa. Levels and trends in caesarean births in the developing world. Stud Fam Plan. 2006;37(1):41-8.

11. Betran AP, Merialdi M, Lauer JA, Bing-shun W, Thomas J, Van-look P, et al. Rates of caesarean section: analysis of global, regional and national estimates. Pediatr Perina Epidemiol. 2007;21:98-113.

12. Naidoo N, Moodley J. Rising rates of caesarean sections in specialist private practice. SA Fam Pract. 2009;51(3):254-8.
13. Barber EL, Lundsberg LS, Belanger K, Penker CM, Funai EF, Illuzzi JL. Indications contributing to the increasing caesarean delivery rate. Obstet Gynecol. 2011;118 29-30.

14. Qazi M, Saqib N. Rising trend of caesarean section in a tertiary care hospital over half a decade: a retrospective study. Int J Reprod Contracept Obstet Gynecol. 2018;7:4097-102.

Cite this article as: Singh N, Manjusha. Are we operating unnecessarily?: caesarean audit in a single unit of a private tertiary care hospital in North India. Int J Reprod Contracept Obstet Gynecol 2020;9:97580 . 